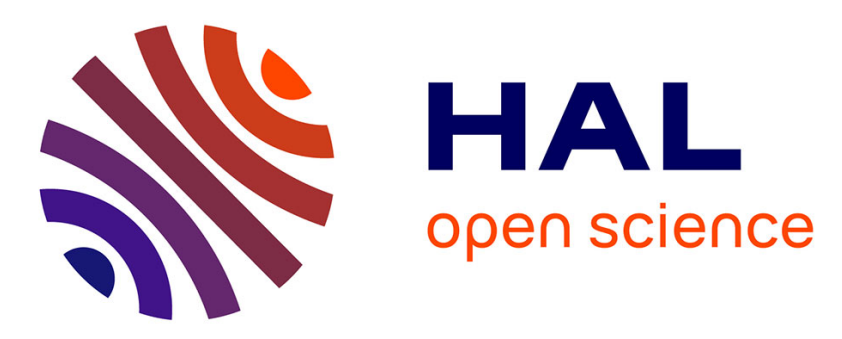

\title{
Line-field confocal optical coherence tomography
}

Jonas Ogien, Olivier Levecq, Hicham Azimani, Arthur Davis, Weikai Xue, David Siret, Jean-Luc Perrot, Arnaud Dubois

\section{To cite this version:}

Jonas Ogien, Olivier Levecq, Hicham Azimani, Arthur Davis, Weikai Xue, et al.. Line-field confocal optical coherence tomography. SPIE's International Symposium on Biomedical Optics (BiOS), Feb 2019, San-Francisco, United States. 10.1117/12.2507244 . hal-02197158

\section{HAL Id: hal-02197158 \\ https://hal-iogs.archives-ouvertes.fr/hal-02197158}

Submitted on 30 Jul 2019

HAL is a multi-disciplinary open access archive for the deposit and dissemination of scientific research documents, whether they are published or not. The documents may come from teaching and research institutions in France or abroad, or from public or private research centers.
L'archive ouverte pluridisciplinaire HAL, est destinée au dépôt et à la diffusion de documents scientifiques de niveau recherche, publiés ou non, émanant des établissements d'enseignement et de recherche français ou étrangers, des laboratoires publics ou privés. 


\title{
Line-field confocal optical coherence tomography
}

\author{
Jonas Ogien ${ }^{\mathrm{a}}$, Olivier Levecq ${ }^{\mathrm{a}}$, Hicham Azimani ${ }^{\mathrm{a}}$, Arthur Davis ${ }^{\mathrm{a}, \mathrm{b}}$, Weikai Xue ${ }^{\mathrm{b}}$, David Siret ${ }^{\mathrm{a}}$, Jean- \\ Luc Perrot ${ }^{\mathrm{c}}$, Arnaud Dubois ${ }^{\mathrm{b}}$ \\ ${ }^{a}$ DAMAE Medical, 28 rue de Turbigo, 75003 Paris, France; ${ }^{b}$ Laboratoire Charles Fabry, Institut \\ d'Optique Graduate School, Université Paris-Sud, 91127 Palaiseau Cedex, France; 'Service \\ dermatologie, CHU St-Etienne, 42055 Saint-Etienne, France
}

\begin{abstract}
We present an improved time-domain optical coherence tomography technique designed for ultrahigh-resolution B-scan imaging in real-time. The technique, called line-field confocal optical coherence tomography, is based on a Linnik-type interference microscope with line illumination using a supercontinuum laser and line detection using a line-scan camera. Bscan imaging with dynamic focusing is achieved by acquiring multiple A-scans in parallel. In vivo cellular level resolution imaging of skin is demonstrated at 10 frame/s with a penetration depth of $\sim 500 \mu \mathrm{m}$, with a spatial resolution of $1.3 \mu \mathrm{m} \times$ $1.1 \mu \mathrm{m}$ (transverse $\times$ axial).
\end{abstract}

Keywords: Optical coherence tomography, medical and biological imaging, interference microscopy.

\section{INTRODUCTION}

Imaging at high spatial resolution using optical coherence tomography (OCT) [1,2] is of particular interest to detect slight morphological changes of tissues associated with the development of tumors, notably in dermatology.

The axial resolution of OCT images is governed by the temporal coherence of the detected light. Axial resolutions of $\sim 1 \mu \mathrm{m}$ have been achieved using efficient broadband light sources including mode-locked lasers [3] and supercontinuum lasers $[4,5]$.

The transverse resolution of OCT images depends on the focusing properties of the light beam that illuminates the sample. In frequency-domain OCT (FD-OCT), the sample reflectivity profile as a function of depth is acquired in parallel, which limits how highly the beam can be focused to preserve a sufficient depth of field (DOF). Several approaches have been investigated to minimize the intrinsic limitation of the transverse resolution in FD-OCT, including the illumination of the sample with a Bessel beam [6-9], or the use of phase masks [10,11]. Computational methods have also been proposed, including interferometric synthetic aperture microscopy [12] and digital refocusing [13-16]. Another approach consists of combining several B-scan images acquired at different depths [17-19]. Despite these advances, however, the transverse resolution in FD-OCT is still limited to a few micrometers.

In time-domain OCT (TD-OCT), the sample reflectivity profile as a function of depth is acquired sequentially by scanning the depth. In TD-OCT, the focus can theoretically be adjusted while the imaging depth is scanned. In practice, however, dynamic focusing is challenging since a tracking speed on the order of a few $\mathrm{m} / \mathrm{s}$ and a repetition rate in the kilohertz range are needed [20-22].

In this paper, we present a TD-OCT technique, called line-field confocal optical coherence tomography (LC-OCT), designed to produce B-scans without the transverse resolution limitation of FD-OCT and without the speed limitation of dynamically-focused TD-OCT. The technology is applied to in vivo cellular-level resolution imaging of human skin.

\section{THE LC-OCT TECHNIQUE}

The experimental setup, depicted in Fig. 1, is based on a Linnik interferometer, i.e. a Michelson interferometer with a microscope objective in each arm. Water-immersion microscope objectives with a numerical aperture of 0.5 are employed. The objective in the reference arm is focused on the external surface of a glass plate that constitutes a reference surface of $\sim 4 \%$ reflectivity. An identical glass plate is placed in the sample arm in contact with the sample. 
The glass plates have a thickness of $500 \mu \mathrm{m}$. A supercontinuum light source is used to generate spatially coherent ultrabroadband light. Line illumination of the sample, with a power of $25 \mathrm{~mW}$, is achieved using a cylindrical lens. Light from the sample and reference arms is recombined by the beam splitter and imaged, using a 200mm-focal length lens, onto a line scan CCD camera. The whole interferometer is mounted on a piezoelectric-driven linear stage for scanning the depth in the sample, as shown in Fig 1.

To minimize optical dispersion mismatch in the interferometer as the imaging depth is increased, the optical dispersion of the microscope objective immersion medium is chosen as close as possible to that of the sample. Silicone oil (refractive index of $\sim 1.4$ ) is used as immersion medium for skin tissue imaging.

The displacement of the piezoelectric actuator is adjusted so that two consecutive images acquired by the line camera correspond to an optical phase-shift of $\sim \pi / 2$ in the interferometer. The range of the depth scan is $500 \mu \mathrm{m}$, which corresponds to the acquisition of stacks of 7000 images (7000 lines). A five-frame phase-shifting algorithm is applied to extract the fringe envelope from the acquired interferometric data [23]. The calculations are performed with a fieldprogrammable gate array (FPGA) to optimize the operation speed. The result of these calculations is a flow of intensitybased B-scan images that are, after being appropriately rescaled, displayed in real-time (10 frame/s) in logarithmic scale with auto-adjusted contrast. Several B-scans can be averaged to reduce noise.

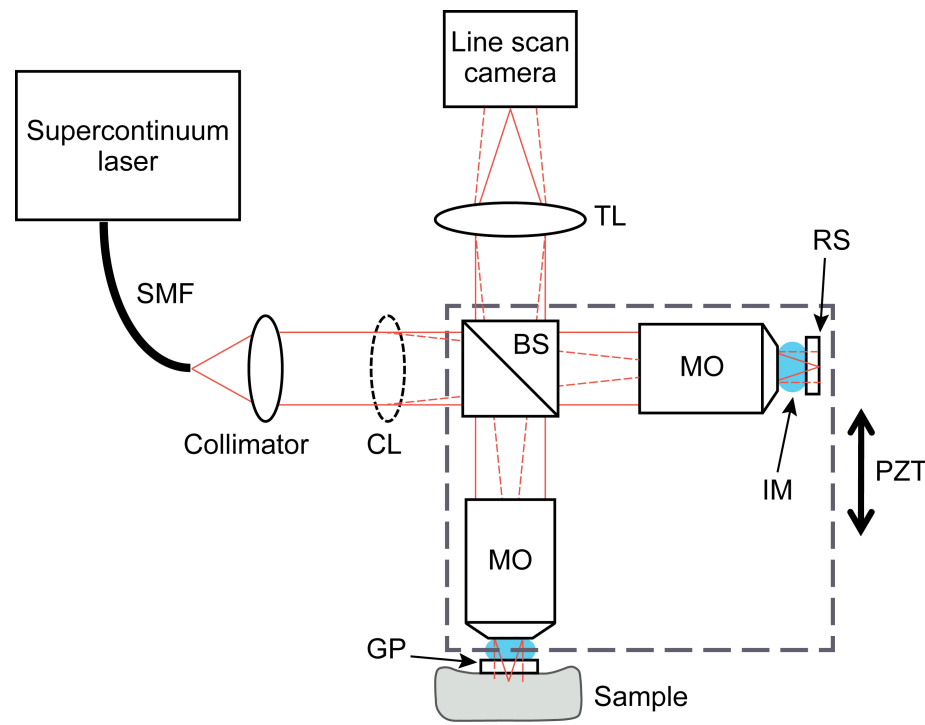

Fig. 1. Schematic of the LC-OCT system. TL: tube lens; RS: reference surface; PZT: piezoelectric actuated translation stage; MO : microscope objective; IM: immersion medium; SMF: single mode fiber; BS: beam-splitter; CL: cylindrical lens. GP: glass plate.

The transverse resolution of the images was estimated by imaging a high-contrast edge, and recording an intensity profile across it. The $20-80 \%$ width of the edge response can be defined as the transverse resolution [24,25]. It was measured to be $1.3 \mu \mathrm{m}$. The axial response of the LC-OCT system was obtained by imaging the interface between the glass plate and air in the sample arm, without using a sample [25]. The full-width-at-half-maximum (FWHM) of the imaged interface was $1.1 \mu \mathrm{m}$, which is considered to be the axial resolution.

The line illumination and line detection implemented in LC-OCT, associated with the use of a high-NA microscope objective to image the sample, provide an efficient confocal gate that prevents most unwanted scattered light to be detected. Furthermore, confocal filtering also reduces the amount of multiple scattered light that may interfere and consequently yield artifacts in the cross-sectional images, thereby limiting the maximal imaging depth and degrading the imaging resolution [26-30].

Each line of an LC-OCT image is calculated from 5 successive lines acquired by the line scan camera. The time required to calculate each line of the LC-OCT image is equal to $5 / f_{c}=71 \mu \mathrm{s}$, where $f_{c}=70 \mathrm{kHz}$ is the camera frame rate. This acquisition time of a few tens of microseconds is similar to the acquisition time of a A-scan in conventional (moderatespeed) FD-OCT. It is short enough to avoid blurring of the phase-sensitive interferometric signal that may occur due to 
sample motion. Image distortion, however, may occur. This artifact is avoided for skin imaging by the mechanical stabilization achieved by pressing the skin against a fixed glass plate.

\section{APPLICATION IN DERMATOLOGY}

Healthy skin was imaged to illustrate the performance of the technique [31]. Fig. 2 shows an example of image of skin from a 30-year-old man on the back of the hand. The epidermis and the dermis, separated by the dermo-epidermal junction, can be easily distinguished. The stratum corneum can also be distinguished as the outermost layer of the epidermis. The nuclei of keratinocyte cells in the epidermis are resolved and appear as black spots. In the dermis, collagen fibers and blood vessels can be observed.

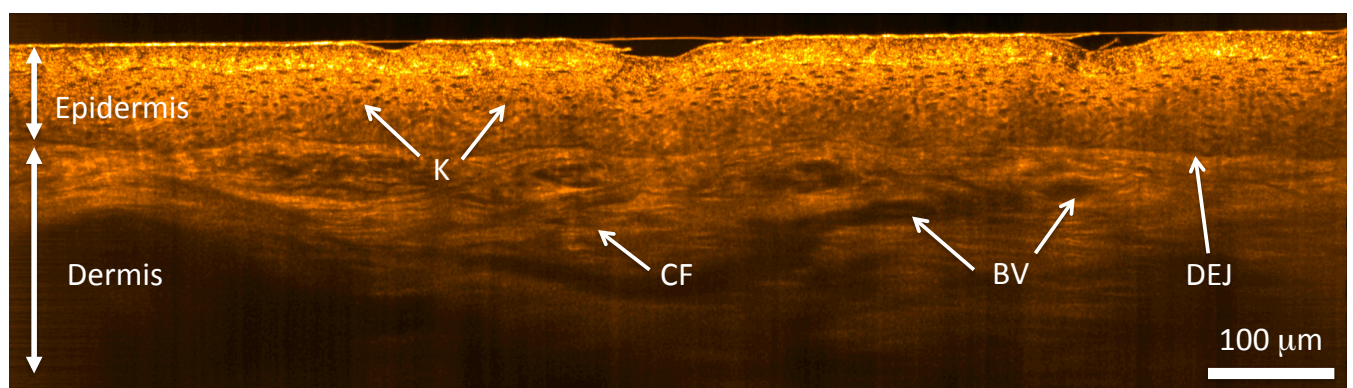

Fig. 2. LC-OCT images of normal skin, in vivo, on the back of the hand. K: keratinocytes; DEJ: dermal-epidermal junction; CF: collagen fibers; BV: blood vessels.

\section{CONCLUSION}

LC-OCT is a TD-OCT technique using line illumination and line detection. By acquiring multiple A-scans in parallel, only one scan (depth scan) is required to produce a B-scan image. The scan of the depth can thus be slower compared to conventional TD-OCT, without increasing the image acquisition time, which makes continuous dynamic focusing easier. A microscope objective with a numerical aperture of 0.5 is dynamically-focused to produce images with a transverse resolution of $1.3 \mu \mathrm{m}$. Moreover, line illumination and detection, combined with a relatively high NA objective lens, provide an efficient confocal gate, which minimizes the amount of unwanted scattered light within the sample that may be detected. Relatively deep imaging in highly scattering tissues can thus be obtained in real-time. By using a supercontinuum laser as the light source and balancing the optical dispersion in the interferometer arms, the axial resolution in LC-OCT reaches $1.1 \mu \mathrm{m}$. In vivo cellular-level imaging in skin has been demonstrated using LC-OCT at 10 frame/s without motion artifacts.

\section{REFERENCES}

[1] D. Huang, E.A. Swanson, C.P. Lin, J.S. Schuman, W.G. Stinson, W. Chang, M.R. Hee, T. Flotte, K. Gregory, C.A. Puliafito, and J.G. Fujimoto, "Optical coherence tomography", Science 254, 1178-1181 (1991).

[2] A. M. Zysk, F. T. Nguyen, A. L. Oldenburg, D. L. Marks, and S. A. Boppart, "Optical coherence tomography: a review of clinical development from bench to bedside," J. Biomed. Opt. 12, 051403 (2007).

[3] W. Drexler, U. Morgner, F. Kärtner, C. Pitris, S. Boppart, X. Li, E. Ippen, and J. Fujimoto, "In vivo ultrahighresolution optical coherence tomography," Opt. Lett. 24, 1221-1223 (1999).

[4] B. Povazay, K. Bizheva, A. Unterhuber, B. Hermann, H. Sattmann, A.F. Fercher, W. Drexler, A. Apolonski, W.J. Wadsworth, J.C. Knight, P.S.J. Russell, M. Vetterlein, and E. Scherzer, "Submicrometer axial resolution optical coherence tomography," Opt. Lett. 27, 1800-1802 (2002).

[5] Y. Wang, Y. Zhao, J.S. Nelson, Zhongping Chen, and R.S. Windeler, "Ultrahigh-resolution optical coherence tomography by broadband continuum generation from a photonic crystal fiber," Opt. Lett. 28, 182-184 (2003). 
[6] Z. Ding, H. Ren, Y. Zhao, J. S. Nelson, and Z. Chen, "High-resolution optical coherence tomography over a large depth range with an axicon lens," Opt. Lett. 27, 243-245 (2002).

[7] R.A. Leitgeb, M. Villiger, A.H. Bachmann, L. Steinmann, and T. Lasser, Opt. Lett. "Extended focus depth for Fourier domain optical coherence microscopy," 31, 2450-2452 (2006).

[8] K. S. Lee, J.P. Rolland, "Bessel beam spectral-domain high-resolution optical coherence tomography with microoptic axicon providing extended focusing range," Opt. Lett. 33, 1696-1698 (2008).

[9] C. Blatter, B. Grajciar, C. M. Eigenwillig, W. Wieser, B. R. Biedermann, R. Huber, and R. A. Leitgeb, "Extended focus high-speed swept source OCT with self-reconstructive illumination," Opt. Express 19, 12141-12155 (2011).

[10] A. Zlotnik, Y. Abraham, L. Liraz, I. Abdulhalim, and Z. Zalevsky, "Improved extended depth of focus full field spectral domain Optical Coherence Tomography,” Opt. Commun. 283, 4963-4968 (2010).

[11] J. Mo, M. de Groot, and J.F. de Boer, "Focus-extension by depth-encoded synthetic aperture in optical coherence tomography," Opt. Express 21, 10048-10061 (2013).

[12] T.S. Ralston, D.L. Marks, P. S. Carney, and S.A. Boppart, "Interferometric synthetic aperture microscopy," Nat. Phys. 3, 129-134 (2007).

[13] L. Yu, B. Rao, J. Zhang, J. Su, Q. Wang, S. Guo, and Z. Chen, "Improved lateral resolution in optical coherence tomography by digital focusing using two-dimensional numerical diffraction method," Opt. Express 15, 7634-7641 (2007).

[14] A. Grebenyuk, A. Federici, V. Ryabukho, and A. Dubois, "Numerically focused full-field swept-source optical coherence microscopy with low spatial coherence illumination," Appl. Opt. 53, 1697-1708 (2014).

[15] D. J. Fechtig, A. Kumar, W. Drexler, and R.A. Leitgeb, "Full range line-field parallel swept source imaging utilizing digital refocusing," J. Mod. Opt. 62, 1801-1807 (2015).

[16] S. Liu, J.A. Mulligan, and S.G. Adie, "Volumetric optical coherence microscopy with a high space-bandwidth-time product enabled by hybrid adaptive optics," Biomed. Opt. Express 9, 3137-3152 (2018).

[17] S. Murali, K. S. Lee, and J. P. Rolland, "Invariant resolution dynamic focus OCM based on liquid crystal lens," Opt. Express 15, 15854-15862 (2007).

[18] J.P. Rolland, P. Meemon, S. Murali, K.P. Thompson, and K-S. Lee, "Gabor-based fusion technique for optical coherence microscopy," Opt. Express 18, 3632-3642 (2010).

[19] J. Holmes, and S. Hattersley, Optical Coherence Tomography and Coherence Domain Optical Methods in Biomedicine XIII, Proc. of SPIE 7168, 71681N (2009).

[20] J.M. Schmitt, S.L. Lee, and K.M. Yung, "An optical coherence microscope with enhanced resolving power in thick tissue," Opt. Commun. 142, 203-207 (1997).

[21] Z. P. Chen, T. E. Milner, D. Dave, and J. S. Nelson, "Optical Doppler tomographic imaging of fluid flow velocity in highly scattering media," Opt. Lett. 22, 64-66 (1997).

[22] F. Lexer, C.K. Hitzenberger, W. Drexler, S. Molebny, H. Sattmann, M. Sticker, and A.F. Fercher, "Dynamic coherent focus OCT with depth-independent transversal resolution," J. Mod. Opt. 46, 541-553 (1999).

[23] K.G. Larkin, "Efficient nonlinear algorithm for envelope detection in white light interferometry," J. Opt. Soc. Am. A 13, 832-843 (1996).

[24] D. Sacchet, J. Moreau, P. Georges, and A. Dubois, "Simultaneous dual-band ultrahigh-resolution full-field optical coherence tomography," Opt. Express 16, 19434-19446 (2008).

[25] A. Dubois, O. Levecq, H. Azimani, A. Davis, J. Ogien, D. Siret, A. Barut, "Line-field confocal time-domain optical coherence tomography with dynamic focusing," Opt. Express 26, 33534-33542 (2018).

[26] J. A. Izatt, E. A. Swanson, J. G. Fujimoto, M. R. Hee, and G. M. Owen, "Optical coherence microscopy in scattering media," Opt Lett 19, 590-592 (1994).

[27] M. J. Yadlowsky, J. M. Schmitt, R. F. Bonner, "Multiple scattering in optical coherence microscopy," Appl. Opt. 34, 5699-5707 (1995).

[28] Y. T. Pan, R. Birngruber, R. Engelhardt, "Contrast limits of coherence-gated imaging in scattering media," Appl. Opt. 36, 2979-2983 (1997).

[29] Q. Lu, X. S. Gan, M. Gu, Q. M. Luo, "Monte Carlo modeling of optical coherence tomography imaging through turbid media," Appl. Opt. 43, 1628 (2004).

[30] Y. Chen, S-W. Huang, A.D. Aguirre, and J.G. Fujimoto, "High-resolution line-scanning optical coherence microscopy," Opt. Lett. 32, 1971-1973 (2007).

[31] A. Dubois, O. Levecq, H. Azimani, D. Siret, A. Barut, M. Suppa, V. Del Marmol, J. Malvehy, E. Cinotti, J.L. Perrot, "Line-field confocal optical coherence tomography for high-resolution noninvasive imaging of skin tumors," J. Biomed. Opt. 23, 106007 (2018). 